\title{
Sugars, the clock and transition to flowering
}

\section{Mohammad R. Bolouri Moghaddam and Wim Van den Ende*}

Laboratory of Molecular Plant Biology, The Katholieke Universiteit Leuven, Leuven, Belgium

\author{
Edited by: \\ Sjef Smeekens, Utrecht University, \\ Netherlands \\ Reviewed by: \\ Sjef Smeekens, Utrecht University, \\ Netherlands \\ Magdalena Gamm, Molecular Plant \\ Physiology, Universiteit Utrecht, \\ Netherlands \\ *Correspondence: \\ Wim Van den Ende, Laboratory of \\ Molecular Plant Biology, The \\ Katholieke Universiteit Leuven, \\ Kasteelpark Arenberg 31, B-3001 \\ Leuven, Belgium. \\ e-mail:wim.vandenende@bio. \\ kuleuven.be
}

Sugars do not only act as source of energy, but they also act as signals in plants. This mini review summarizes the emerging links between sucrose-mediated signaling and the cellular networks involved in flowering time control and defense. Cross-talks with gibberellin and jasmonate signaling pathways are highlighted. The circadian clock fulfills a crucial role at the heart of cellular networks and the bilateral relation between sugar signaling and the clock is discussed. It is proposed that important factors controlling plant growth (DELLAs, PHYTOCHROME INTERACTING FACTORS, invertases, and trehalose-6phosphate) might fulfill central roles in the transition to flowering as well. The emerging concept of "sweet immunity," modulated by the clock, might at least partly rely on a sucrose-specific signaling pathway that needs further exploration.

\section{Keywords: circadian clock, DELLA, flowering time, invertase, PIF, sugar signaling, sweet immunity, T6P}

\section{INTRODUCTION}

In addition to their role as providers of carbon and energy, sugars fulfill a signaling role in coordination with hormonal signaling pathways (Rolland et al., 2006) controlling various plant physiological processes, probably also including innate immunity (Bolouri Moghaddam and Van den Ende, 2012). Distinct glucose, sucrose, and fructose signaling pathways can be discerned (Cho and Yoo, 2011; Li et al., 2011). These signaling pathways may be strongly influenced by the activities of sucrose splitting enzymes (vacuolar, cell wall and neutral invertases, sucrose synthase or SuSy; Koch, 2004) since they have strong impact on sucrose to hexose ratios, which might be an important parameter in plant responses, especially under stress (Xiang et al., 2011). It can be speculated that cellular sucrose to hexose ratios translate into certain levels of trehalose-6-phosphate (T6P), an emerging regulatory molecule in plant growth and stress responses (Lunn et al., 2006; Vandesteene et al., 2012; Wingler et al., 2012). T6P levels are likely controlled by the balance between its synthesis from UDPGlc and glucose 6-phosphate (G6P) by trehalose-6-phosphate synthase (TPS) and its breakdown by trehalose-6-phosphate phosphatase (TPP; Lunn et al., 2006).

Next to growth and stress responses, it can be expected that sugar signaling is of great importance in flowering time control. This major developmental transition directly affects yield and its exact timing is essential for plant fitness (Amasino, 2010; Huang etal., 2012). In many plant species, floral transition is strongly controlled by the circadian clock. The clock with a period close to $24 \mathrm{~h}$ serves to coordinate diurnal rhythms with physiology and behavior. The clock consists of three autoregulatory interlocked transcriptional feedback loops (Harmer, 2009; Troncoso-Ponce and Mas, 2012). Briefly, the central feedback loop contains the CIRCADIAN CLOCK ASSOCIATED 1 (CCA1), LATE ELONGATED HYPOCOTYL (LHY), and TIMING OF CAB EXPRESSION 1 (TOC1) as crucial players. Both
CCA1 and LHY contribute to the second loop as positive regulators of PSEUDO RESPONSE REGULATORS 7 (PRR7) and PRR9, which are negative regulators of CCA1 and LHY (Nakamichi et al., 2009). TOC1 acts as a negative regulator of GIGANTEA (GI).

In this mini review, focus is on the possible contributions of sugar signaling to flowering and immunity responses, under control of the circadian clock.

\section{CIRCADIAN REGULATION OF FLOWERING}

In Arabidopsis, flowering can be autonomous or induced by gibberellins (GAs), as internal signals, or by the photoperiod and vernalization as external signals. FLOWERING LOCUS T (FT), SUPPRESSOR OF OVEREXPRESSION OF CONSTANS 1 (SOC1), SQUAMOSA PROMOTER BINDING PROTEIN-LIKE (SPL) and LEAFY (LFY) transcription factors are among the best characterized floral pathway integrators, next to others (Matsoukas et al., 2012; Yamaguchi and Abe, 2012). Both FT and SOC1 are inhibited by FLOWERING LOCUS C (FLC) in the autonomous and vernalization dependent pathways, while FT and SOC1 are activated by the photoperiodic protein CONSTANS (CO; Lee and Lee, 2010). During the day-night cycle, rhythmic expression of the core circadian clock components, CCA1, LHY, and TOC1 control the expression of GI, an activator of CO (Murphy et al., 2011).

The induction of flowering through the transport of phloemmobile signals (FT and GA) to the apex is well-documented (Corbesier et al., 2007; Tamaki et al., 2007; Turnbull, 2011; Matsoukas et al., 2012; Yu et al., 2012). It is known since long that phloem-mobile sucrose may represent an additional critical factor in controlling the transition to flowering (Corbesier et al., 1998; Roldan et al., 1999; Ohto etal., 2001). This would represent another function for sucrose next to its known roles in many other plant regulatory and signaling mechanisms including growth, development, and stress-related responses (Wind et al., 2010). 
PLACING FLOWERING INTO THE BIGGER PICTURE: CENTRAL ROLES FOR DELLAS AND miRNAs

DELLA proteins are crucial players in GA signaling pathways involved in plant growth control (Harberd et al., 2009; Figure 1). GA inhibits DELLA protein levels, which are inhibitors of PHYTOCHROME INTERACTING FACTORS (PIFs), acting as growth enhancers (Nozue etal., 2011; Stewart etal., 2011; Figure 1). Recently, miR156 and miR172 were found as important factors controlling plant developmental transitions (Yamaguchi and Abe, 2012). It was found that miR 156 acts as a negative regulator of SPL gene expression. SPLs stimulate LFY and MADS box genes (Borner et al., 2000; Vekemans et al., 2012) and the production of miR172, which in turn stimulates reproductive competency and flowering through its inhibitory action on APETALA2 (AP2), TARGET OF EAT1 (TOE), SCHLAFMÜTZE (SMZ), and SCHNARCHZAPEN (SNZ), inhibitors of FT (Zhu and Helliwell, 2010; Yamaguchi and Abe, 2012; Figure 1). miR172 is also under control of the clock by GI (Jung et al., 2007; Figure 1). The missing mechanistic link between GA signaling and flowering was recently established, by defining a role for DELLA as a general flowering inhibitor. DELLA inhibits SPL gene expression and miR172 production (Galvao et al., 2012; Yu et al., 2012; Figure 1). Therefore, DELLA proteins are now considered both as growth and flowering inhibitors. Accordingly, transgenic plants overexpressing DELLA proteins or plants expressing mutant DELLA repressors show dwarfism and delayed flowering (Dill et al., 2004; Hamama et al., 2012). What is more, at lower GA levels, some DELLA proteins were found to act as strong activators of the jasmonate (JA) signaling pathway (Wild et al., 2012), a major pathway controlling plant defense responses (Yang et al., 2012; Figure 1). It can be concluded that DELLAs occupy a central and crucial position in plant growth, development and flowering as well as in stress responses (Figure 1).

\section{HOW DO SUGAR SIGNALS INTERACT WITH FLOWERING NETWORKS?}

The relation between sugar metabolism/signaling and floral transition received extensive attention lately (Turnbull, 2011; King, 2012). The work of Heyer et al. (2004) already provided clear evidence that flowering time control is strongly influenced by modifying sugar balances in the apex. They placed yeast invertase under the control of a meristem-specific promoter and compared apoplastic and cytosolic localized invertase versions. Intriguingly, transition to flowering was hastened by the expression of the invertase in the cell wall, while a flowering delay was observed when the invertase was expressed in the cytosol. This indicated that invertases with a different localization might fulfill a crucial role in transition to flowering. It was recently proposed that high sucrose levels are associated with high T6P levels (Wingler et al., 2012), but it should be noted that this correlation depends on the activity of sucrose splitting enzymes, such as invertases (Figure 1). Although the molecular mechanism for the control of transition to flowering by sugars remains to be further investigated, a possible scenario is that T6P rather than sucrose acts as a signal in such processes (Figure 1). Indeed, transgenic plants with altered T6P levels are also affected in their flowering time (Avonce et al., 2004; van Dijken etal., 2004; Gomez etal., 2010; Ponnu etal., 2011). It can be speculated that the T6P signal is integrated into the miR156/SPL node of the floral induction pathway (Matsoukas et al., 2012). Although the exact molecular mechanisms remain to be further explored, a possible scenario is that T6P acts as a positive mediator of some PIF isoforms (Figure 1). Indeed, it was reported that PIF5 overexpression leads to early flowering, both under long day and short day conditions (Nozue et al., 2011), strongly suggesting that PIFs might be linked to floral transition. Moreover, in hypocotyl elongation studies it was found that sucrose stimulates several PIF isoforms, even in the dark (Liu et al., 2011; Stewart et al., 2011; Lilley et al., 2012; Sairanen et al., 2012). Therefore, similar to DELLA proteins which were only recently recognized as important players in flowering time control, it can be expected that some PIF isoforms may be involved as well. However, it remains to be demonstrated whether such underlying PIF-mediated mechanisms account for the stimulation of FT gene expression by sucrose (King et al., 2008; Figure 1). Also, it would be interesting to investigate the mechanisms involved in the sucrosemediated upregulation of the LFY gene (Matsoukas et al., 2012; Figure 1). Another emerging link between flowering and sucrose metabolism/transport was reported by Seo et al. (2011). These authors demonstrated that the INDETERMINATE DOMAIN 8 (IDD8) transcription factor plays a role in FT-dependent flowering induction, via modulation of the SuSy4 activity. Further, Coneva et al. (2012) reported that the starch to sucrose transition is important during autonomous flowering. In conclusion, sucrose seems to interact in many ways with the flowering network, and further studies are needed to fully understand these connections at the molecular level.

\section{HOW DOES SUGAR SIGNALING INTERACT WITH THE CLOCK?}

On the one hand, it was recently reported that the clock's core central oscillator genes GI, TOC1, and CCA1 are stimulated by sucrose (Knight et al., 2008; Dalchau et al., 2011), suggesting that the clock is entrained by metabolic signals such as sugars, possibly independent from phytochrome-mediated light perception. On the other hand, it has been demonstrated that the enzymatic activity and expression of a vacuolar invertase gene in petioles of sugar beet follows a circadian rhythm (González et al., 2005). Furthermore, it is well-known that vacuolar invertases are stimulated by GA (González and Cejudo, 2007; Choubane et al., 2012). A function of vacuolar invertases as stimulators of stomatal opening has recently been suggested (Antunes et al., 2012; Ni, 2012), in addition to their well-described role in cellular elongation processes (Wang et al., 2010). These observations fit well with the overall idea that invertases fulfill a central (Figure 1) and crucial role coordinating carbon dioxide uptake, photosynthesis, and plant growth through GA- and sugar-mediated signaling pathways, with a clear connection to the flowering time control network (Figure 1), as explained above. Intriguingly, expression of FT in guard cells also promoted stomatal opening (Kinoshita et al., 2011). This suggests a role for FT in stimulating carbon dioxide uptake and fixation, to produce the necessary carbon skeletons that are required for the flowering process.

Noteworthy, the cell wall invertase LIN6 of tomato, induced by JA signaling and considered as a pivotal enzyme for the integration of various signals, is also regulated by a diurnal rhythm (Proels and Roitsch, 2009). Intriguingly, the rhythms of the 


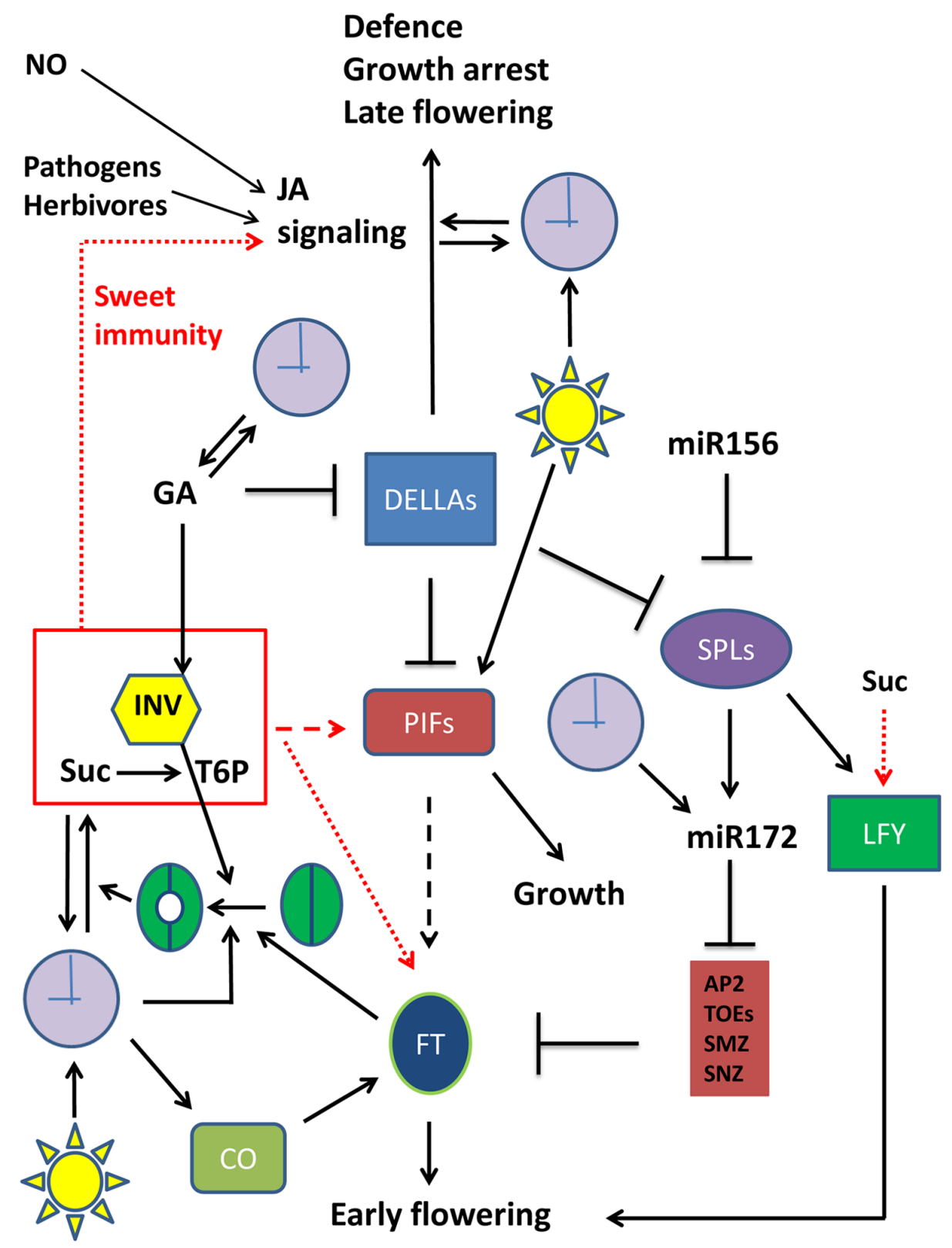

FIGURE 1 | Emerging sugar signaling connections to cellular networks involved in plant growth, defense, and floral transition. Simplified schematic presentation of a selection of crucial players in plant growth, flowering transition, and defense responses, and their interactions.

Metabolites are not boxed, proteins are in colored boxes. Arrows $(\rightarrow)$ signify stimulation, while an inhibitory interaction is presented by the $\dashv$ symbol. Red arrows refer to the putative effect of the Suc/INV/T6P module. Full arrows indicate established relationships. Dotted arrows indicate established relationships that are in need for further exploration (unraveling of

mechanistic details). Dashed arrows represent rather speculative connections that remain to be confirmed. Straightforward symbols are used for light and the clock. Stomatal opening is also schematically presented. APA2, APETALA2; CO, CONSTANS; DELLA, DELLA protein; FT, Flowering locus T; $\mathrm{GA}$, gibberellin; INV, invertase (or any other sucrose splitting enzyme); JA, jasmonate; LFY, LEAFY; miR156, micro RNA 156; miR172, micro RNA 172; NO, nitric oxide; PIF, Phytochrome Interacting factor; SPL, Squamosa Promoter Binding Protein-like; Suc, sucrose; TOE, TARGET OF EAT1; SMZ, SCHLAFMÜTZE; SNZ, SCHNARCHZAPEN. For more details on floral transition networks, readers are referred to Matsoukas et al. (2012) and Yu etal. (2012), where apex- and leaf-located processes are discerned. two above-mentioned vacuolar and cell wall invertases were not synchronized, perhaps reflecting differential diurnal patterns in growth dynamics.

These and other observations strongly suggest that there is an intimate interplay and reciprocal relationship between sugar metabolism/signaling and the plant circadian clock. So, besides light as the most important stimulus influencing the clock's components through phytochromes and cryptochromes, endogenous sugar signals, hormones, and stresses also entrain the clock (Arana et al., 2011; Facella et al., 2012; Goodspeed et al., 2012; 
Seung et al., 2012). Vice-versa, the clock is involved in regulating the biosynthesis of GA (Blázquez et al., 2002) and JA (Shin et al., 2012), suggesting that the clock shows putative bilateral relationships with these hormones as well (Figure 1).

\section{SUGAR SIGNALING IN RHYTHMIC IMMUNITY}

Sugars as signaling molecules are well-known activators of various pattern-recognition receptor genes (Johnson and Ryan, 1990; Herbers etal., 1996a,b). There is mounting evidence that, in addition to plant cell wall or fungal-derived oligosaccharides, also sugars such as sucrose could be involved in plant priming and innate immunity responses (Gomez-Ariza et al., 2007; Birch et al., 2009; Bolouri Moghaddam and Van den Ende, 2012; Sonnewald etal., 2012). One of the best studied pathways in plant defense responses is the sucrose-specific signaling pathway that leads to the production of anthocyanins (Teng et al., 2005; Solfanelli etal., 2006). Despite huge research efforts, a number of (transcription) factors involved in this pathway remain to be identified. Possibly T6P is involved (Wingler et al., 2012), but the underlying mechanisms need further investigation. During sucrose-mediated signaling, $\mathrm{Ca}^{2+}$ seems to be involved as well, probably by stimulating sucrose uptake into the cell (Shin et al., 2013). Both light and most plant hormones influence this pathway (reviewed in Das etal., 2012). Nitric oxide (NO) and pathogen-derived elicitors are also able to trigger the production of anthocyanins (Tossi etal., 2011; Cai et al., 2012; Figure 1). Strikingly, transgenic plants expressing a mammalian NO synthase become disease resistant to a broad array of plant pathogens (Chun et al., 2013) highlighting the importance of NO signaling. Perhaps NO is an integral part of the sucrose-specific pathway leading to anthocyanin production, and this is an interesting area of further investigation. Furthermore, NO was found to regulate DELLA contents and PIF expression (Lozano-Juste and Leon, 2011). The effect of sugar signaling on plant immunity may, at least partly, depend on the expression and activation of kinases such as the mitogen-activated protein kinases (MAPKs). It has been recently demonstrated that sucrose can rapidly activate CfSAPK, a unique sucrose-specific MAPK from Cephalostachyum fuchsianum (Li et al., 2012), but it is unknown whether other plants (such as Arabidopsis) also have such sucrose-specific MAPKs.

It has been shown that many plant factors involved in plant immune responses are regulated by the clock (Faris et al., 2010; Bhardwaj et al., 2011; Wang et al., 2011). Plants probably evolved this type of regulation to maximize levels of defense compounds (toxins, defense hormones) and/or sweet immunostimulators at those moments of the day when the encounter with the

\section{REFERENCES}

Amasino, R. (2010). Seasonal and developmental timing of flowering. Plant J. 61, 1001-1013.

Antunes, W. C., Provart, N. J., and Loureiro, M. E. (2012). Changes in stomatal function and water use efficiency in potato plants with altered sucrolytic activity. Plant Cell Environ. 35, 747-759.
Arana, V. M., Marin-de la Rosa, N., Maloof, J. N., Blazquez, M. A., and Alabadi, D. (2011). Circadian oscillation of gibberellin signaling in Arabidopsis. Proc. Natl. Acad. Sci. U.S.A. 108, 9292-9297.

Avonce, N., Leyman, B., Mascorro Gallardo, J. O., Van Dijck, P., and Thevelein, J. M. (2004). The Arabidopsis trehalose-6-P synthase AtTPS1 gene is a regulator of

pathogen/herbivore is more likely to occur. For instance, JA levels show a diurnal oscillation that is synchronized with insect feeding behavior (Goodspeed et al., 2012). Similarly, a clockcontrolled variation in resistance to the virulent bacterial pathogen Pseudomonas syringae pv. tomato DC3000 (Pst DC3000) was discovered in Arabidopsis (Bhardwaj et al., 2011).

Interestingly, flowering time control and defense signaling pathways in plants seem to have points of convergence too (Liu et al., 2012). The rice spotted leaf 11 mutant shows an enhanced resistance to Magnaporthe grisea and Xanthomonas oryzae pv oryzae (Yin et al., 2000; Liu et al., 2012; Marino et al., 2012) and the spotted leaf 11 gene expression is induced by both incompatible and compatible rice-blast interactions (Zeng et al., 2004). Moreover, the spotted leaf 11 protein is involved in flowering time regulation in rice (Liu et al., 2012). This dual role in control of flowering time and defense has also been demonstrated for the Arabidopsis ortholog Plant U-box 13, but the molecular mechanisms involved and the possible links with sugar signaling events remain unclear.

\section{CONCLUSION}

Many aspects of plant growth, development, floral transition, and defense responses are regulated by circadian rhythms as well as by sugar signaling events. This mini review focused on the emerging links between sugar signaling, the clock, floral transition, and immune responses. Overall, GA and JA signaling pathways greatly determine plant growth versus defense responses, with DELLA and PIF proteins as central players. The recent finding that some DELLA proteins are also key players in floral transition urges further research on the possible involvement of PIFs in floral transition processes, since some data suggest that PIF expression may be under direct control by sugar signals, perhaps mediated by T6P. Invertases may be important to control T6P levels, taking a central position in these networks. Furthermore, putative new roles are emerging for invertases (e.g., stomatal opening).

It is also proposed that efficient defense responses might not only rely on hormones and on cell wall or pathogen-derived saccharides, but perhaps also on sucrose, through a sucrose-specific signaling pathway, perhaps (partly) resembling (or overlapping) with the sucrose-mediated pathway controlling anthocyanin biosynthesis in Arabidopsis. However, the putative sucrose sensor acting in this pathway remains to be identified, as well as the (transcription) factors involved in the upper part of the pathway, and this remains a challenging task.

\section{ACKNOWLEDGMENT}

Wim Van den Ende is supported by grants from FWO Vlaanderen.

glucose, abscisic acid, and stress signaling. Plant Physiol. 136, 36493659.

Bhardwaj, V., Meier, S., Petersen, L. N., Ingle, R. A., and Roden, L. C. (2011). Defence responses of Arabidopsis thaliana to infection by Pseudomonas syringae are regulated by the circadian clock. PLOS ONE 6:e26968. doi: 10.1371/journal.pone. 0026968
Birch, A. N. E., Shep herd, T., Hancock, R., and Goszcz, K. (2009). "Understanding sugar sensing in induced plant defences and stress tolerance," in Proceedings of the 25th Meeting of the International Society of Chemical Ecology, 23-27 August 2009, Neuchatel, Switzerland, 230.

Blázquez, M. A., Trènor, M., and Weigel, D. (2002). Independent control of gibberellin biosynthesis and 
flowering time by the circadian clock in Arabidopsis. Plant Physiol. 130, 1770-1775.

Bolouri Moghaddam, M. R., and Van den Ende, W. (2012). Sugars and plant innate immunity. J. Exp. Bot. 63, 3989-3998.

Borner, R., Kampmann, G., Chandler, J., Gleissner, R., Wisman, E., Apel, K., et al. (2000). A MADS domain gene involved in the transition to flowering in Arabidopsis. Plant J. 24, 591-599.

Cai, Z. Z., Kastell, A., Mewis, I., Knorr, D., and Smetanska, I. (2012). Polysaccharide elicitors enhance anthocyanin and phenolic acid accumulation in cell suspension cultures of Vitis vinifera. Plant Cell Tissue Organ Cult. 108, 401-409.

Cho, Y. H., and Yoo, S. D. (2011). Signaling role of fructose mediated by FINS1/FBP in Arabidopsis thaliana. PLoS Genet. 6:e1001263. doi: 10.1371/journal.pgen.1001263

Choubane, D., Rabot, A., Mortreau, E., Legourrierec, J., Peron, T., Foucher, F., et al. (2012). Photocontrol of bud burst involves gibberellin biosynthesis in Rosa sp. J. Plant Physiol. 169, 1271-1280.

Chun, H. J., Park, H. C., Koo, S. C., Lee, J. H., Park, C. J., Choi, M. S., et al. (2013). Constitutive expression of mammalian nitric oxide synthase in tobacco plants triggers disease resistance to pathogens. Mol. Cells 34, 463-471.

Coneva, V., Guevara, D., Rothstein, S. J., and Colasanti, J. (2012). Transcript and metabolite signature of maize source leaves suggests a link between transitory starch to sucrose balance and the autonomous floral transition. J. Exp. Bot. 63, 5079-5092.

Corbesier, L., Lejeune, P., and Bernier, G. (1998). The role of carbohydrates in the induction of flowering in Arabidopsis thaliana, comparison between the wild type and a starchless mutant. Planta 206, 131-137.

Corbesier, L., Vincent, C., Jang, S. H., Fornara, F., Fan, Q. Z., Searle, I., et al. (2007). FT protein movement contributes to long distance signaling in floral induction of Arabidopsis. Science 316, 1030-1033.

Dalchau, N., Baek, S. J., Briggs, H. M., Robertson, F. C., Dodd, A. N., Gardner, M., et al. (2011). The circadian oscillator gene GIGANTEA mediates a long-term response of the Arabidopsis thaliana circadian clock to sucrose. Proc. Natl. Acad. Sci. U.S.A. 108, 5104-5109.

Das, P. K., Shin, D. H., Choi, S. B., and Park, Y.-I. (2012). Sugarhormone cross-talk in anthocyanin biosynthesis. Mol. Cells 34, 501-507.
Dill, A., Thomas, S. G., Hu, J. H., Steber, C. M., and Sun, T. P. (2004). The Arabidopsis F-box protein SLEEPY1 targets gibberellin signaling repressors for gibberellin-induced degradation. Plant Cell 16, 1392-1405.

Facella, P., Daddiego, L., Giuliano, G., and Perrotta, G. (2012). Gibberellin and auxin influence the diurnal transcription pattern of photoreceptor genes via CRYla in tomato. PLoS ONE 7:e30121. doi: 10.1371/journal.pone.0030121

Faris, J. D., Zhang, Z., Lu, H., Lu, S., Reddy, L., Cloutier, S. et al. (2010). A unique wheat disease resistance-like gene governs effector-triggered susceptibility to necrotrophic pathogens. Proc. Natl. Acad. Sci. U.S.A. 107, $13544-$ 13549.

Galvao, V. C., Horrer, D., Kuettner, F., and Schmid, M. (2012). Spatial control of flowering by DELLA proteins in Arabidopsis thaliana. Development 139, 4072-4082.

Gomez-Ariza, J., Campo, S., Rufat, M., Estopa, M., Messeguer, J., San Segundo, B., et al. (2007). Sucrosemediated priming of plant defence responses and broad-spectrum disease resistance by overexpression of the maize pathogenesis-related PRms protein in rice plants. Mol. Plant Microbe Interact. 20, 832-842.

Gomez, L. D., Gilday, A., Feil, R. Lunn, J. E., and Graham, I. A. (2010). AtTPS1-mediated trehalose 6-phosphate synthesis is essential for embryogenic and vegetative growth and responsiveness to ABA in germinating seeds and stomatal guard cells. Plant J. 64, 1-13.

González, M. C., and Cejudo, F. J. (2007). Gibberellin-regulated expression of neutral and vacuolar invertase genes in petioles of sugar beet plants. Plant Sci. 172, 839-846.

González, M. C., Roitsch, T., and Cejudo, F. J. (2005). Circadian and developmental regulation of vacuolar invertase expression in petioles of sugar beet plants. Planta 222, 386-395.

Goodspeed, D., Chehab, E. W., Min-Venditti, A., Braam, J., and Covington, M. F. (2012). Arabidopsis synchronizes jasmonate-mediated defence with insect circadian behavior. Proc. Natl. Acad. Sci. U.S.A. 12, 4674-4677.

Hamama, L., Naouar, A., Gala, R., Voisine, L., Pierre, S., Jeauffre, J., et al. (2012). Overexpression of RoDELLA impacts the height, branching, and flowering behaviour of Pelargonium $\mathrm{x}$ domesticum transgenic plants. Plant Cell Rep. 31, 2015-2029.
Harberd, N. P., Belfield, E., and Yasumura, Y. (2009). The angiosperm gibberellin-GID1-DELLA growth regulatory mechanism: how an "inhibitor of an inhibitor" enables flexible response to fluctuating environments. Plant Cell 21, 1328-1339.

Harmer, S. L. (2009). The circadian system in higher plants. Ann. Rev. Plant Biol. 60, 357-377.

Herbers, K., Meuwly, P., Frommer, W. Mètraux, J. P., and Sonnewald, U. (1996a). Systemic acquired resistance mediated by the ectopic expression of invertase: possible hexose sensing in the secretory pathway. Plant Cell 8 , 793-803.

Herbers, K., Meuwly, P., Mètraux, J. P., and Sonnewald, U. (1996b). Salicylic acid independent induction of pathogenesis-related protein transcripts by sugars is dependent on leaf developmental stage. FEBS Lett. 397, 239-244.

Heyer, A. G., Raap, M., Schroeer, B., Marty, B., and Willmitzer, L. (2004). Cell wall invertase expression at the apical meristem alters floral, architectural, and reproductive traits in Arabidopsis thaliana. Plant J. 39, 161-169.

Huang, H., Yan, P., Lascoux, M., and Ge, X. (2012). Flowering time and transcriptome variation in Capsella bursa-pastoris (Brassicaceae). New Phytol. 194, 676-689.

Johnson, R., and Ryan, C. A. (1990). Wound-inducible potato inhibitor II genes: enhancement of expression by sucrose. Plant Mol. Biol. 14, 527-536.

Jung, J.-H., Seo, Y.-H., Seo, P. J., Reyes, J. L., Yun, J., Chua, N.-H., et al. (2007). The GIGANTEA-regulated MicroRNA172 mediates photoperiodic flowering independent of CONSTANS in Arabidopsis. Plant Cell 19, 2736-2748.

King, R. W. (2012). Mobile signals in day length-regulated flowering: gibberellins, flowering locus $\mathrm{T}$, and sucrose. Russ. J. Plant Physiol. 59, 479-490.

King, R. W., Hisamatsu, T., Goldschmidt, E., and Blundell, C. (2008). The nature of floral sig nals in Arabidopsis. I. Photosynthesis and a far-red photoresponse independently regulate flowering by increasing expression of FLOWER ING LOCUS T (FT). J. Exp. Bot. 59, 3811-3820.

Kinoshita, T., Ono, N., Hayashi, Y., Morimoto, S., and Nakamura, S. (2011). FLOWERING LOCUS T regulates stomatal opening. Curr. Biol. 21, 1232-1238.
Knight, H., Thomson, A. J. W., and McWatters, H. G. (2008). Sensitive to freezing6 integrates cellular and environmental inputs to the plant circadian clock. Plant Physiol. 148, 293-303.

Koch, K. (2004). Sucrose metabolism: regulatory mechanisms and pivotal roles in sugar sensing and plant development. Curr. Opin. Plant Biol. 7, 235-246.

Lee, J., and Lee, I. (2010). Regulation and function of SOC1, a flowering pathway integrator. J. Exp. Bot. 61, 2247-2254.

Li, L. B., Li, Y., Zhang, L., Xu, C. H., Su, T. B., Ren, D. T., et al. (2012). Sucrose induces rapid activation of CfSAPK, a mitogen-activated protein kinase in Cephalostachyum fuchsianum gamble cells. Plant Cell Environ. 35, 14281439.

Li, P., Wind, J. J., Shi, X., Zhang, H., Hanson, J., Smeekens, S. C., et al. (2011). Fructose sensitivity is suppressed in Arabidopsis by the transcription factor NAC089 lacking the membrane-bound domain. Proc. Natl. Acad. Sci. U.S.A. 108, 3436-3441.

Lilley, J. L., Gee, C. W., Sairanen, I., Ljung, K., and Nemhauser, J. L. (2012). An endogenous carbonsensing pathway triggers increased auxin flux and hypocotyl elongation. Plant Physiol. 160, 22612270.

Liu, J., Li, W., Ning, Y., Shirsekar, G., Wang, X., Dai, L., et al. (2012). The U-box E3 ligase SPL11/PUB13 is a convergence point of defense and flowering signaling in plants. Plant Physiol. 160, 28-37.

Liu, Z., Zhang, Y., Liu, R., Hao, H., Wang, Z., and Bi, Y. (2011). Phytochrome Interacting Factors (PIFs) are essential regulators for sucroseinduced hypocotyl elongation in Arabidopsis. J. Plant Physiol. 168, 1771-1779.

Lozano-Juste, J., and Leon, J. (2011). Nitric oxide regulates DELLA content and PIF expression to promote photomorphogenesis in Arabidopsis. Plant Physiol. 156, 1410-1423.

Lunn, J. E., Hendriks, J., Feil, R., Carillo, P., Gibon, Y., Morcuende, R., et al. (2006). Sugar-induced increases in trehalose 6-phosphate are correlated with redox activation of ADPglucose pyrophosphorylase and higher rates of starch synthesis in Arabidopsis thaliana. Biochem. J. 397, 139-148.

Marino, D., Peeters, N., and Rivas, S. (2012). Ubiquitination during plant immune signaling. Plant Physiol. 160, 15-27. 
Matsoukas, I. G., Massiah, A. J., and Thomas, B. (2012). Florigenic and antiflorigenic signaling in plants. Plant Cell Physiol. 53, $1827-$ 1842.

Murphy, R. L., Klein, R., Morishige, D. T., Brady, J. A., and Rooney, W. L. (2011). Coincident light and clock regulation of pseudoresponse regulator protein 37 (PRR37) controls photoperiodic flowering in sorghum. Proc. Natl. Acad. U.S.A. 108, 1646916474.

Nakamichi, N., Kusano, M., Fukushima, A., Kita, M., Ito, S., Yamashino, T., etal. (2009). Transcript Profiling of an Arabidopsis PSEUDO RESPONSE REGULATOR arrhythmic triple mutant reveals a role for the circadian clock in cold stress response. Plant Cell Physiol. 50, 447-462.

Ni, D. A. (2012). Role of vacuolar invertase in regulating Arabidopsis stomatal opening. Acta Physiol. Plant. 34, 2449-2452.

Nozue, K., Harmer, S. L., and Maloof, J. N. (2011). Genomic analysis of circadian clock-, light-, and growth-correlated genes reveals PHYTOCHROME-INTERACTING FACTOR5 as a modulator of auxin signaling in Arabidopsis. Plant Physiol. 156, 357-372.

Ohto, M., Onai, K., Furukawa, Y., Aoki, E., Araki, T., and Nakamura, K. (2001). Effects of sugar on vegetative development and floral transition in Arabidopsis. Plant Physiol. 127, 252-261.

Ponnu, J., Wahl, V., and Schmid, M. (2011). Trehalose 6-phosphate: connecting plant metabolism and development. Front. Plant Sci. 2:70. doi: 10.3389/fpls.2011.00070

Proels, R. K., and Roitsch, T. (2009). Extracellular invertase LIN6 of tomato: a pivotal enzyme for integration of metabolic, hormonal, and stress signals is regulated by a diurnal rhythm. J. Exp. Bot. 60, 15551567.

Roldan, M., Gomez-Mena, C., RuizGarcia, L., Salinas, J., and MartinezZapater, J. M. (1999). Sucrose availability on the aerial part of the plant promotes morphogenesis and flowering of Arabidopsis in the dark. Plant J. 20, 581-590.

Rolland, F., Baena-Gonzalez, E., and Sheen, J. (2006). Sugar sensing and signaling in plants: conserved and novel mechanisms. Ann. Rev. Plant Biol. 57, 675-709.

Sairanen, I., Novák, O., Pencík, A., Ikeda, Y., Jones, B., Sandberg, G., et al. (2012). Soluble carbohydrates regulate auxin biosynthesis via PIF proteins in Arabidopsis. Plant Cell 24, 4907-4916.

Seo, P. J., Ryu, J., Kang, S. K., and Park, C. M. (2011). Modulation of sugar metabolism by an INDETERMINATE DOMAIN transcription factor contributes to photoperiodic flowering in Arabidopsis. Plant J. 65, 418-429.

Seung, D., Risopatron, J. P. M., Jones, B. J., and Marc, J. (2012). Circadian clock-dependent gating in ABA signalling networks. Protoplasma 249, 445-457.

Shin, D. H., Choi, M. G., Lee, H. K., Cho, M., Choi, S. B., Choi, G., et al. (2013). Calcium dependent sucrose uptake links sugar signaling to anthocyanin biosynthesis in Arabidopsis. Biochem. Biophys. Res. Commun. 430, 634-639.

Shin, J., Heidrich, K., SanchezVillarreal, A., Parker, J. E., and Davis, S. J. (2012). TIME FOR COFFEE represses accumulation of the MYC2 transcription factor to provide timeof-day regulation of jasmonate signaling in Arabidopsis. Plant Cell 24 2470-2482.

Solfanelli, C., Poggi, A., Loreti, E., Alpi, A., and Perata, P. (2006). Sucrosespecific induction of the anthocyanin biosynthetic pathway in Arabidopsis. Plant Physiol. 140, 637-646.

Sonnewald, S., Priller, J. P. R., Schuster, J., Glickmann, E., Hajirezaei, M.-R., Siebig, S., et al. (2012). Regulation of cell wall-bound invertase in pepper leaves by Xanthomonas campestris pv. vesicatoria type three effectors. PLoS ONE 7:e51763. doi: 10.1371/journal.pone.0051763

Stewart, J. L., Maloof, J. N., and Nemhauser, J. L. (2011). PIF genes mediate the effect of sucrose on seedling growth dynamics. PLoS ONE 6:e19894. doi: 10.1371/journal.pone.0019894

Tamaki, S., Matsuo, S., Wong, H. L. Yokoi, S., and Shimamoto, K. (2007). $\mathrm{Hd} 3 \mathrm{a}$ protein is a mobile flowering signal in rice. Science 316, 1033-1036.

Teng, S., Keurentjes, J., Bentsink, L., Koornneef, M., and Smeekens, S.(2005). Sucrose-specific induction of anthocyanin biosynthesis in Arabidopsis requires the MYB75/PAP1 gene. Plant Physiol. 139, 18401852.

Tossi, V., Amenta, M., Lamattina, L. and Cassia, R. (2011). Nitric oxide enhances plant ultraviolet-B protection up-regulating gene expression of the phenylpropanoid biosynthetic pathway. Plant Cell Environ. 34, 909-921.

Troncoso-Ponce, M. A., and Mas, P. (2012). Newly described components and regulatory mechanisms of circadian clock function in Arabidopsis thaliana. Mol. Plant 5, 545-553.

Turnbull, C. (2011). Long-distance regulation of flowering time. J. Exp. Bot. 62, 4399-4413.

Vandesteene, L., Lopez Galvis, L., Vanneste, K., Feil, R., Maere, S. Lammens, W., et al. (2012). Expansive evolution of the trehalose-6phosphate phosphatase gene family in Arabidopsis. Plant Physiol. 160, 884-896.

van Dijken, A. J. H., Schluepmann, H., and Smeekens, S. C. M. (2004). Arabidopsis trehalose-6phosphate synthase 1 is essential for normal vegetative growth and transition to flowering. Plant Physiol. 135, 969-977.

Vekemans, D., Proost, S., Vanneste, K., Coenen, H., Viaene, T., Ruelens, P., et al. (2012). Gamma paleohexaploidy in the stem lineage of core eudicots: significance for MADS-Box gene and species diversification. Mol. Biol. Evol. 29, 3973-3806.

Wang, L., Li, X. R., Lian, H., Ni, D. A., He, Y. K., Chen, X. Y., et al. (2010) Evidence that high activity of vacuolar invertase is required for cotton fiber and Arabidopsis root elongation through osmotic dependent and independent pathways, respectively. Plant Physiol. 154, 744-756.

Wang, W., Barnaby, J. Y., Tada, Y., Li, H., Tor, M., Caldelari, D., et al. (2011). Timing of plant immune responses by a central circadian regulator. Nature 470, 110-126.

Wild, M., Daviere, J., Cheminant, S., Regnault, T., Baumberger, N., Heintz, D., et al. (2012). The Arabidopsis DELLA RGA-LIKE3 is a direct target of MYC2 and modulates jasmonate signaling responses. Plant Cell 24, 3307-3319.

Wind, J., Smeekens, S., and Hanson, J. (2010). Sucrose: metabolite and signaling molecule. Phytochemistry 71, 1610-1614.

Wingler, A., Delatte, T. L., O'Hara, L. E., Primavesi, L. F., Jhurreea, D. Paul, M. J., et al. (2012). Trehalose 6phosphate is required for the onset of leaf senescence associated with high carbon availability. Plant Physiol. 158, 1241-1251.

Xiang, L., Le Roy, K., Bolouri Moghaddam, M. R., Vanhaecke, M., Lammens, W., Rolland, F., et al. (2011). Exploring the neutral invertase-oxidative stress defence connection in Arabidopsis thaliana. J. Exp. Bot. 62, 38493862.

Yamaguchi, A., and Abe, M. (2012). Regulation of reproductive development by non-coding RNA in Arabidopsis: to flower or not to flower. J. Plant Res. 125, 693-704.

Yang, D. L., Yao, J., Mei, C. S., Tong, X. H., Zeng, L. J., Li, Q., et al. (2012). Plant hormone jasmonate prioritizes defense over growth by interfering with gibberellin signaling cascade. Proc. Natl. Acad. Sci. U.S.A. 109, E1192-E1200.

Yin, Z., Chen, J., Zeng, L., Goh, M., Leung, H., Khush, G. S., et al. (2000). Characterizing rice lesion mimic mutants and identifying a mutant with broad-spectrum resistance to rice blast and bacterial blight. Mol. Plant Microbe Interact. 13, 869-876.

Yu, S., Galvao, V. C., Zhang, Y.-C., Horrer, D., Zhang, T.-Q., Hao, Y.-H., et al. (2012).Gibberellin regulates the Arabidopsis floral transition through miR156-targeted SQUAMOSA PROMOTER BINDING-LIKE transcription factors. Plant Cell 24, 3320-3332.

Zeng, L. R., Qu, S., Bordeos, A., Yang, C., Baraoidan, M., Yan, H., et al. (2004). Spotted leaf11, a negative regulator of plant cell death and defense, encodes a U-box/armadillo repeat protein endowed with E3 ubiquitin ligase activity. Plant Cell 16, 2795-2808.

Zhu, Q.-H., and Helliwell, C. A. (2010). Regulation of flowering time and floral patterning by miR172. J. Exp. Bot. 62, 487-495.

Conflict of Interest Statement: The authors declare that the research was conducted in the absence of any commercial or financial relationships that could be construed as a potential conflict of interest.

Received: 20 November 2012; accepted: 29 January 2013; published online: 14 February 2013.

Citation: Bolouri Moghaddam MR and Van den Ende W (2013) Sugars, the clock and transition to flowering. Front. Plant Sci. 4:22. doi: 10.3389/fpls.2013.00022

This article was submitted to Frontiers in Plant Physiology, a specialty of Frontiers in Plant Science.

Copyright (c) 2013 Bolouri Moghaddam and Van den Ende. This is an openaccess article distributed under the terms of the Creative Commons Attribution License, which permits use, distribution and reproduction in other forums, provided the original authors and source are credited and subject to any copyright notices concerning any third-party graphics etc. 